\title{
Krisis Dalam Arkeologi Indonesia
}

\section{Mindra Faizaliskandiar}

Keywords: archaeology; methods; paradigm; theory; indonesia

\section{How to Cite:}

Faizaliskandiar, M. (1991). Krisis Dalam Arkeologi Indonesia. Berkala Arkeologi, 12(1), 48-64. https://doi.org/10.30883/jba.v12i1.558

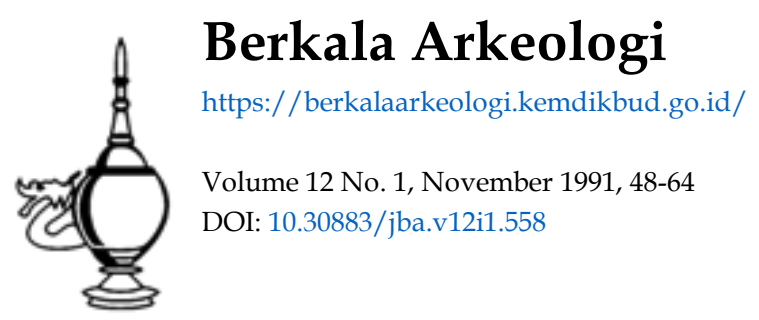




\section{KRISIS DALAM ARKEOLOGI INDONESIA}

Mindra Faizal iskandiar

\section{Paradigma Keilmuan}

Banyak orang mengakui, tidaklah mudah menjelaskan pengertian "ilmu" (science)", terlebih bila penjelasan itu harus dibuat secara singkat dan sederhana. Secara umum ilmu dapat dijelaskan sebagai perangkat untuk mengumpulkan pengetahuan tertentu dan kumpulan pengetahuan tertentu itu sendiri. Pengetahuan tertentu itu mempunyai ciri-ciri tersendiri yang membedakannya dengan pengetahuan lainnya. Kumpulan pengetahuan tersebut merupakan struktur yang kompleks, yang diperoleh lewat metode ilmiah tertentu. Keseluruhan hal itulah yang saya maksudkan di sini dengan "paradigma keilmuan" (scientific paradigm).

Suatu pemikiran menarik tentang paradigma keilmuan -- yang cukup besar pengaruhnya terutama di kalangan ilmuwan Amerika Serikat (Chalmers 1983: 94), termasuk juga para ahli arkeologinya (lihat misalnya Willey dan Sabloff 1974) -- adalah buah pikiran Thomas Kuhn dalam bukunya The Structure of Scientific Revolution, diterbitkan pertamakali tahun 1962 (Kuhn 1970).

1 Penerjemahan kata "science" menjadi "ilmu" pun sesungguhnya masih menjadi bahan perdebatan seru di kalangan ilmuwan. Ada yang lebih suka menerjemahkannya dengan "ilmu pengetahuan", dan ada pula yang memakai kata "ilmu" untuk "science" dan "pengetahuan" untuk "knowledge". Bahkan muncul pula pendapat lain, yang mengindonesiakan kata "science", menjadi "sains" (Lihat misalnya Jujun Suriasumantri 1984: 291-296; Vredenbergt 1984; Van Peursen 1985; Beerling dkk. 1986; Sutarjo Adisusilo 1983; Mangunwijaya 1983; van Melsen 1985; dan Teuku Jacob 1988). Dalam karangan ini saya sendiri cenderung menggunakan istilah "ilmu" untuk "science" dan "pengetahuan" untuk "knowledge". 
Kuhn memulai karir akademisnya sebagai ahli fisika dan kemudian mengalihkan perhatiannya pada sejarah ilmu. Dalam mengamati sejarah ilmu, Kuhn merasa bahwa asumsi-asumsi awalnya tentang watak ilmu - yang semula diyakininya -- ternyata kemudian harus diakuinya tidak tepat lagi. Ia mulai menyadari bahwa pandangan tradisional tentang ilmu, apakah itu pandangan induktif maupun deduktif, sama-sama tidak mampu bertahan dalam sejarah ilmu. Sejak itu teori-teori Kuhn tentang ilmu kemudian dikembangkan sebagai usaha untuk menjadikan teori tentang ilmu lebih sesuai dengan situasi sejarah ilmu (Chalmers 1983: 93).

Mengenai sejarah ilmu, Kuhn menggambarkannya dalam bentuk skema dengan akhir terbuka: "prailmu-ilmu normal - krisis - revolusi - ilmu normal baru krisis baru - revolusi baru - .." ", dan begitu berulang-ulang. Dalam kategori prailmu, para ilmuwan. melakukan aktivitasnya secara terpisah dan tidak terorganisir. Dengan kata lain, pada kategori awal ini masih belum tercipta suatu paradigma keilmuan yang secara bulat diakui dan dianut oleh suatu masyarakat ilmiah disiplin ilmu yang bersangkutan. Dalam kategori berikutnya -- Kuhn menyebutnya "ilmu normal" (normal science) -- paradigma tunggal itu telah tercipta. Ditegaskannya bahwa ilmu yang sudah matang dikuasai oleh suatu paradigma tunggal. Paradigma tunggal itulah yang menetapkan standar pekerjaan, mengkoordinasi dan memimpin aktivitas di dalam lingkungan ilmu yang bersangkutan.

Kuhn menggambarkan paradigma tunggal itu dalam kata-katanya sendiri sebagai berikut:

"... Scientific community acquires with a paradigm is a criterion for choosing problems that, while the paradigm is taken for granted, can be assumed to have solutions. To a great extent these are the only problems that the community will admit as scientific or encourage its members to undertake. Other problems, including many that had previously been standard, are 
rejected as metaphysical, as the concern of another discipline, or sometimes as just too problematic to be worth the time. A paradigm can, for that matter, even insulate the community from those socially important problems that are not reducible to the puzzle form, because they cannot be stated in terms of the conceptual and instrumental tools the paradigm supplies" (Kuhn 1970: 37).

Eksistensi sebuah ilmu normal, menurut Kuhn, ditandai oleh suatu paradigma keilmuan yang diakui dan dianut oleh seluruh komunitas ilmu yang bersangkutan. Akan tetapi paradigma keilmuan itu sendiri ternyata sulit untuk didefinisikan dalam batasan-batasan yang bersifat pasti. Kuhn sendiri menyatakan bahwa upaya untuk menjabarkan ciri-ciri eksplisit dari suatu paradigma keilmuan adalah upaya yang tidak mungkin (Kuhn 1970: 67-68).

Namun sekalipun tidak ada ciri-ciri yang lengkap dan eksplisit dari suatu paradigma, para ilmuwan dapat memperoleh pengetahuan suatu paradigma melalui pendidikan ilmiah. Dengan cara memecahkan masalah-masalah yang baku, melaksanakan pelbagai latihan-latihan, dan akhirnya mencoba melakukan penelitian sendiri di bawah bimbingan ilmuwan yang sudah menguasai paradigma, maka seorang ilmuwan dapat menguasai metodemetode, teknik-teknik, dan standar paradigma tersebut. Ilmuwan itu sendiri memang tidak akan mampu memberikan uraian eksplisit tentang metode-metode dan keterampilan yang telah diperolehnya itu -- seperti tukang kayu tidak akan mampu menguraikan selengkapnya apa yang ada di belakang keterampilannya (Chalmers 1983: 98).

Meskipun demikian, Kuhn sendiri bersikeras bahwa keadaan itu tidak lantas menyebabkan konsep paradigma sudah tidak dapat dipertahankan lagi. Meskipun tidak akan lengkap dan menyeluruh, ciri-ciri suatu paradigma masih dapat dikemukakan, minimal ciri-ciri utama yang 
portant, during revolutions scientists see new and different things when looking with familiar instruments in places they have looked before" (Kuhn 1970: 111).

\section{Paradigma Ilmu Arkeologi: Problem Definisi}

Apakah arkeologi mempunyai paradigmanya sendiri? Untuk menjawab pertanyaan $1 \mathrm{n}$, pertama-tama kita mesti membahas persoalan yang pernah dilontarkan arkeolog Inggris pada tahun 1950-an, Sir Mortimer W'heeler:

"I do not even know wether archaeology is to be described as an art or as a science?" (Wheeler 1954:2)2.

Sebuah pertanyaan mendasar lantas menjadi penting, arkeologi termasuk ilmu atau seni? ${ }^{3}$ Seolah menjawab pertanyaan ini, arkeologi Amerika James F. Deetz menulis:

"As a part of cultural anthropology, archaeology is legitimately as social science" (Deetz 1971:3).

Akan tetapi sampai di sini masalahnya tidak lantas menjadi usai. Apakah hanya karena sebagai bagian dari ilmu antropologi budaya saja arkeologi dapat disebut ilmu? Untuk menjelaskan persoalan ini, kita simak pendapat Martha Joukowsky, arkeolog wanita dari Amerika Serikat.

2 Sedangkan Encyclopaedia Britannica (Vol. 2, Chicago-London: William Benton Publishers, 1960, hlm. 232) mengartikan arkeologi sebagai: "... is that science or art - it can be maintained that it is both - which is concerned with the material remains of man's past".

3 Meskipun filsuf kenamaan, Will Durant, dalam bukunya The Story of Philosophy (New York: Simon \& Schuster, 1933: 2) pernah berujar: "Tiap ilmu dimulai dengan filsafat dan diakhiri dengan seni...", seperti yang dikutip Jujun Suriasumantri (1984: 24-25), namun untuk arkeologi pertanyaan tersebut tetap terasa aktual. 
tampak sangat menonjol di dalam paradigma yang bersangkutan. Pendek kata, Kuhn masih meyakini kekuatan konsep paradigma keilmuannya.

Lebih lanjut Kuhn menyatakan bahwa di dalam sejarah ilmu, pada suatu ketika akan terjadi suatu kondisi di mana paradigma tunggal yang telah sekian lama diakui dan dianut itu menemui banyak hambatan untuk terus dipakai. Akibatnya para ilmuwan merasa tidak puas lagi pada paradigma tunggal tersebut. Keadaan inilah yang dimaksudkan Kuhn sebagai "krisis" (Kuhn 1970: 66-76). Krisis akan teratasi bila lahir paradigma tunggal baru, yang dipercaya dan diyakini masyarakat ilmiah disiplin ilmu yang bersangkutan, untuk kemudian sama sekali menggantikan paradigma tunggal sebelumnya. Proses inilah yang dimaksudkan Kuhn dengan "revolusi keilmuan" (Kuhn 1970: 92).

Perubahan suatu paradigma keilmuan dianggap Kuhn sebagai ciri utama dari proses revolusi keilmuan. Menurut pandangan Kuhn tentang perkembangan ilmu, setiap paradigma selalu mempunyai kemungkinan untuk menjadi tidak layak dalam batas-batas tertentu, dan apabila ketidaklayakan tersebut berkembang menjadi masalah yang serius - artinya suatu "krisis" mulai muncul -- maka langkah revolusioner untuk menggantikan paradigma lama dengan paradigma baru menjadi teramat mendesak untuk kemajuan suatu ilmu. Kemajuan melalui suatu revolusi adalah alternatif Kuhn untuk perkembangan ilmu (Chalmers 1983: 104).

Demikianlah, revolusi keilmuan menurut Kuhn adalah digantikannya suatu paradigma tunggal yang lama dengan paradigma tunggal yang baru. Selanjutnya paradigma tunggal yang baru itulah yang akan membimbing aktivitas "ilmu normal baru", atau seperti yang dikemukakan Kuhn:

"... Led by a new paradigm, scientists adopt new instruments and look in new places. Even more im- 
"Archaeos means ancient, and logos means word, discussion or reason. By definition, then, archaeology is the science by which the remains of ancient man can be methodically and systematically studied to obtain as a complete a picture as possible of ancient culture and society and thereby to reconstruct past ways of life. It is a discipline that involves study, observation, recording, and experiment.-Archaeologists study in detail the complete life of cultures and their patterns of change in attempt to delineate the causes and effects of the cultural process" (Joukowsky 1980: 2). ${ }^{4}$

Sampai di sini barangkali bisa kita sepakati, arkeologi adalah ilmu. ${ }^{5}$ Seperti juga disiplin ilmu yang lain,

Disiplin ilmu arkeologi mempunyai data, metode, dan tujuan keilmuan tersendiri dalam aktivitasnya. Arkeologi juga mengenal pelbagai metode yang umųm dikenal dalam ilmu-ilmu lainnya, seperti metode sampling, induktif dan deduktif, survei, statistik, dan sebagainya. Kalau begitu mengapa kita harus menjadi bingung dan mempertanyakan apakah arkeologi termasuk seni atau ilmu? 6

4 Kamus The Oxford Universal Dictionary, 1955, seperti yang dikutip Willey dan Sabloff (1974: 11) mengartikan arkeologi sebagai: "(1) The ancient history generally; systematic description or study of antiquities; and (2) The scientific study of the remains and monuments of the prehistoric period..."

5 Leslie A. White $(1949: \ldots)$ menyatakan: "Scientists are not people who wear white lab coats or have offices in science buildings or subscribe to 'science' magazine. The scientists is one who uses the scientific method to abstract universals from a world of particulars. It is that simple."

6 Satu-satunya alasan untuk menggolongkan arkeologi sebagai seni adalah karena di awal pertumbuhannya, arkeologi lebih banyak berbicara masalah-masalah seni, seperti seni arca, seni arsitektur, seni ukir, seni pahat, seni sastra, dan sebagainya. 
Akan tetapi, kalau James Deetz menyatakan bahwa sebagai bagian dri ilmu antropologi budaya maka arkeologi termasuk ilmu sosial, berarti arkeologi bukanlah ilmu yang berdiri sendiri. Masalah ini terasa menjadi lebih menarik lagi kalau kita ingat ungkapan Willey dan Phillips yang amat populer itu:

"Archaeology is anthropology or it is nothing..." (Willey dan Phillips 1970: 2). ${ }^{\text {? }}$

Sementara David Clarke, arkeolog Inggris yang mendefinisikan arkeologi sebagai ilmu yang memusatkan perhatian pada usaha menemukan kembali, mendeskripsikan secara sistematik, serta mengamati dan mempelajari kebudayaan materi masa lalu, lebih lanjut mengatakan:

"Archaeological data are not historical data and consequently archaeology is not history" (Clarke 1978: $10-11) .8$

Jelas memang bahwa data arkeologi amatlah berbeda dengan data ilmu sejarah. Kalau ilmu sejarah lebih memusatkan perhatian pada peristiwa-peristiw di masa lalu lewat data tertulis, atau bahkan lewat data yang diperoleh dari wawancara dengan pelaku sejarah, maka arkeologi lebih memusatkan perhatian pada bentuk-bentuk kebudayaan masa lalu berdasarkan data tak tertulis, yaitu data yang bersifat artefaktual.

7 Seorang tokoh Arkeologi Amerika lainnya, Lewis R. Binford, nampaknya lebih menyetujui pendapat arkeologi sebagai subdisiplin ilmu antropologi (periksa Binford 1972a), meskipun pada akhirnya ia menyatakan: "... such a change could go far in advancing the field of archaeology spesifically, and would certainly advance the general field of anthropology" (Binford 1972a: 32). Lihat juga Longacre (1964).

8 Sementara seorang ahli arkeologi kenamaan lain, stuart Pigott, secara tegas menyatakan bahwa arkeologi adalah cabang ilmu sejarah (Daniel 1967: 1; Pigott 1965). 
Dengan demikian terdapat suatu paradigma, yang terutama dianut kebanyakan ahli Arkeologi Amerika, bahwa arkeologi bukanlah ilmu sejarah. Arkeologi mungkin bisa disebut sebagai subdisiplin ilmu antropologi, atau kalaupun hal itu tidak dapat diterima, maka arkeologi adalah disiplin ilmu yang berdiri sendiri. Seolah mempertegas pendapatnya, Clarke melanjutkan kalimat di atas dengan:

"The view taken in this work is that archaeology is archeology is archaeology" (Clarke 1978: 11).

Lewat pernyataan di atas, kita sampai pada kesimpuln bhwa arkeologi adalah arkeologi. Arkeologi tidak sama dengan antropologi dan juga bukan ilmu sejarah. Arkeologi adalah disiplin ilmu yang berdiri sendiri, lengkap dengan data, metode, dan tujuannya sendiri. Arkeologi mempunyai paradigmanya sendiri, yang berbeda baik dengan antropologi maupun ilmu sejarah. Arkeologi adalah arkeologi.

Akan tetapi kalau pada masa-masa sebelumnya orang mengenal arkeologi sebagai ilmu yang hanya mencakup kebudayaan masa lalu saja, Michael B. Schiffer dan kawan-kawannya mengajukan pendapat baru yang cukup kontroversial. Schiffer, Reid, dan Rathje secara eksplisit menyatakan:

"... the subject matter of archaeology is the relationships between human behavior and material culture in all times and places" (Schiffer 1976:4).9

${ }^{9}$ Arkeologi dalam pengertian tersebut oleh Schiffer disebut Arkeologi Perilaku (behavioral archaeology). Lebih lanjut Schiffer mengemukakan 4 strategi dasar penelitian Arkeologi Perilaku, yang mencakup bentuk "ideografik" dan "nomotetik" (untuk jelasnya lihat Schiffer 1976: 4-10). 
Lewat pernyataan ini, Schiffer dkk. telah mendorong disiplin ilmu arkeologi untuk terus berkembang, dan sama sekali mengubah citra arkeologi di mata dunia. Akibat pernyataan tersebut, terjadi pergeseran dan perluasan ruang lingkup jelajahan disiplin ilmu arkeologi. Dengan demikian arkeologi tidak lagi melulu bicara masalah kapak batu prasejarah atau bangunan suci dari masa Klasik saja. Penelitian arkeologis yang dilakukan oleh William L. Rathje di kota Tucson, Arizona (USA) pada tahun 1971-1975 merupakan salah satu "produk" dari pernyataan di atas. Dengan penelitian yang disebut Garbage Project itu, Rathje meneliti sampah dalam masyarakat kontemporer untuk mengamati hubungan mianusia dengan kebudayaan materinya (Rathje 1974 dan 1978). 10

\section{Problem Arkeologi Indonesia: Paradigma Lama dan Baru}

Sekarang masalahnya adalah, bagaimana dengan arkeologi di Indonesia? Sampai tahun 1960-an, arkeologi di Indonesia masih kerap disebut sebagai "ilmu purbakala" (Soekmono 1965) atau "ilmu sejarah kebudayaan kuno" (Koentjaraningrat 1974: 18). Namun sejak tahun 1970an, istilah yang lebih sering dipakai adalah "arkeologi"

10 David Hurst Thomas mengomentari aktivitas Rathje tersebut: "... by initiating the Garbage Project, Rathje was attempting to apply archaeological methods to the analysis and description of modern societies" (Thomas 1979: 417). Rathje sendiri berpendapat bahwa arkeologi cukup punya hak untuk ikut menyelidiki kehidupan masyarakat modern, dan pengalaman arkeologi yang bertahun-tahun bergelut dengan kebudayaan materi akan cukup bermanfaat untuk menyelidiki beberapa kasus dalam masyarakat modern (Rathje 1974 dan 1978). Di Indonesia, penelitian tentang sampah seperti yang telah dilakukan oleh Rathje itu sebenarnya juga pernah dilakukan oleh beberapa arkeolog muda di Jakarta (lihat Sonny Wibisono dkk. 1988). 
(Mundardjito 1972; 1977; 1981a; 1981b; 1982; 1983; Mundardjito dkk. 1978; Soejatmi Satari 1977; Soejono 1976; 1977; Bambang Soemadio 1980; dan Satyawati Suleiman 1977). 11

Bagaimana perigertian arkeologi di Indonesia? Prof. Dr. Soekmono, seorang putra Indonesia pertama yang memperoleh predikat ahli arkeologi, secara implisit pernah mengungkapkan bahwa arkeologi di Indonesia adalah ilmu yang mempelajari manusia masa lalu lewat kebudayaan materi yang ditinggalkannya (Soekmono 1965). Dengan demikian, pengertian arkeologi di Indonesia relatif sama dengan pengertian arkeologi di beberapa negara lain.

Akan tetapi, seandainya kita amati dengan lebih seksama, sesungguhnya terdapat sedikit kekhususan dalam tubuh arkeologi di Indonesia. Ciri khusus dalam arkeologi di Indonesia itu nampaknya dipengaruhi oleh sejarah kemunculan dan perkembangannya selama inı. Tokoh-tokoh awal dalam kemunculan dan pengembangan arkeologi di Indonesia adalah para sarjana Belanda, yang kebanyakan bahkan tidak berlatar pendidikan arkeologis, melainkan filologis (Mindra Faizaliskandiar 1985: 41-43).

Agaknya harus kita akui bahwa arkeologi di Indonesia lahir dari para sarjana filologi Belanda. Selama masa abad ke-19,12 karangan para sarjana Belanda tentang Indonesia yang kemudian mencakup juga bidang epigrafi,

11 Istilah "arkeologi" ini secara tidak langsung diresmikan lewat pengukuhan nama lembaga resmi Pusat Penelitian Arkeologi Nasional se jak tahun 1980.

12 Abad ke-19 ini diakui sebagai abad lanirnya arkeologi sebagai ilmu di Eropa. Demikian antara lain pendapat Henry Margenau dan David Bergamini, dua ahli sejarah ilmu, dalam bukunya The Scientist (New York: Time Inc., 1964), seperti yang dikutip oleh Jujun Suriasumantri (1981: 14-15). 
banyak ditulis dan diterbitkan dalam pelbagai majalah ilmiah. Para sarjana filologi yang kemudian berminat pula untuk membahas pelbagai prasasti itu, lambat laun -- mungkin karena isi prasasti yang dibacanya - tertarik pula untuk meneliti sejarah kuno Indonesia. Minat pada sejarah kuno inilah yang kemudian menarik perhatian mereka pada peninggalan arkeologis, karena banyak peninggalan arkeologis dapat dipakai sebagai data tambahan untuk meneliti dan melengkapi sejarah kuno Indonesia. Mula-mula, peninggalan arkeolgis yang menarik perhatian mereka adalah peninggalan dari masa Klasik, akan tetapi lalu meluas hingga peninggalan dari masa prasejarah dan Islam.

Demikianlah, arkeologi di Indonesia memang dibawa oleh para filolog Belanda, dan karena kajian filologi hampir selalu mengacu kepada kajian sejarah, maka akibatnya kajian arkeologis di Indonesia pun lebih dekat mengacu kepada kajian sejarah. Itulah sebabnya pendidikan tinggi arkeologi pun mengacu kepada mendidik calon ahli arkeologi yang dekat ke arah ahli ilmu sejarah. Pada awalnya, Program Studi Arkeologi di fakultasfakultas sastra UI, UGM, UNUD, maupun UNHAS juga ditempatkan di Jurusan Ilmu-ilmu Sejarah, bersama-sama dengan Program Studi Sejarah. Demikianlah, ilmu arkeologi yang dikembangkan di universitas-universitas itu pada awalnya adalah ilmu arkeologi yang diwarnai ilmu sejarah. Pembagian spesialisasi ilmu arkeologi -- Prasejarah, Klasik, Islam -- yang berdasarkan kriteria zaman itu (Mindra Faizaliskandiar, 1990) juga mirip dengan spesialisasi dalam ilmu sejarah di Indonesia. Bahkan spesialisasi prasejarah pun lebih mengacu kepada kajian "sejarah" dengan objek studi masa sebelum mengenal tulisan. Paradigma ilmu arkeologi yang secara konseptual lebih mengacu kepada ilmu sejarah itu di sini saya namakan sebagai "kecenderungan lama".

Akan tetapi kalau kita amati sejarah perkembangan ilmu arkeologi di Indonesia dengan lebih seksama, nam- 
paklah bahwa sejak tahun 1980-an mulai muncul kecenderungan yang tidak lagi mengacu kepada paradigma lama. Mindra Faizaliskandiar (1985) pernah mencoba mengamati sejarah perkembangan arkeologi di Indonesia lewat kajian atas skripsi-skripsi sarjana arkeologi di Universitas Indonesia, yang terentang antara tahun 1953-1984. Berdasarkan kajian itu nampak bahwa mulai tahun 1980 telah muncul skripsi-skripsi yang tidak lagi sepenuhnya menggunăkan paradigma lama, selain skripsiskripsi yang masih menggunakan paradigma tersebut. Kalau diukur prosentasenya, kecenderungan baru itu semakin lama semakin membesar, sedangkan kecenderungan lama menunjukkan grafik yang menurun. Paradigma ilmu arkeologi yang secara konseptual lebih mengacu kepada ilmu antropologi budaya adalah yang saya sebut di sini sebagai "kecenderungan baru".

Kalau kita terapkan konsep skema perkembangan ilmu menurut Thomas Kuhn, maka nampaknya situasi dan kondisi ilmu arkeologi di Indonesia antara 19801989 dapat dikategorikan sebagai "krisis", yaitu bahwa paradigma lama mulai ada yang menganggapnya telah menjadi tidak layak dalam batas-batas tertentu. Dan ketidaklayakan tersebut semakin lama telah berkembang menjadi masalah yang serius. Menurut hemat saya, "krisis" itu juga mulai tampak pada benturan-benturan pendapat antara sarjana arkeologi lulusan pra-1980 dengan mereka yang lulus pasca-1980. Batasan tahun lulusan ini tentu saja bisa dikoreksi, akan tetapi benturan-benturan pendapat -- baik yang diam-diam maupun yang terungkap ke permukaan - nampak jelas semakin kerap terjadi. Batasan tahun lulusan itu juga tidak mesti bersifat mutlak, karena dalam kenyataannya banyak miereka yang lulus pra-1980 telah mengembangkan persepsinya ke arah kecenderungan baru. Bahkan kalau bicara jujur, tokoh-tokoh pionir pengembangan kecenderungan baru itu adalah mereka yang lulusan pra-1980 itu, misalnya saja Mundardjito dan Bambang Sumadio dari UI, serta Ph. Soebroto dan Timbul Haryono dari UGM. 
Pertentangan kecenderungan lama dan baru, secara ekstrim dan emosional memang bisa mengacu kepada sentimen pribadi. Akan tetapi dipandang dari sudut etika ilmuwan dan etika ilmiah, pertentangan seperti itu bukan saja tak terhindarkan, melainkan memang harus terjadi. Justru lewat pertentangan seperti itulah suatu disiplin ilmu dapat melangkah semakin maju. Akan tetapi tentu saja "pertentangan ilmiah" itu harus dilakukan dengan kepala dingin dan tanpa syak-wasangka. Dan sejak awal mesti ditanamkan kesadaran bahwa pertentangan itu tidak harus diakhiri dengan ada yang menang dan kalah, melainkan harus dilanjutkan dengan maju dan berkembangnya disiplin ilmu arkeologi di Indonesia. 


\section{KEPUSTAKAAN}

Abu Sidik Wibowo "Riwayat Penyelidikan Prasasti di Indonesia", dalam Satyawati Suleiman et al. (eds.), 50 Tahun Lembaga Peninggalan Purbakala Nasional, Jakarta, Puslit Arkenas, hlm. 60-103.1977.

Bambang Soemadio, "Masalah Penelitian Sejarah Kuno Melalui Kegiatan Arkeologi di Indonesia", dalam Satyawati Suleimen et al. (eds.), Pertemuan Ilmiah Arkeologi 1977, Jakar ta: Puslit Arkenas, hlm, 587 - 598.

Beerling; Kwee; Mooij; dan Van Peursen. Pengantar Filsafat Ilmu. Terj. Soejono Soemargono, Yogyakarta: PT. Tiara Wacana Yogya. 1986.

Bergamini, David et al. (eds.). Pustaka Ilmu Life: Ilmuwan. Jakarta: Penerbit Kanisius. 1980. Pustaka Ilmu Life: Matematika. Jakarta: Penerbit Kanisius. 1981.

Binford, Lewis R. 1972. An Archaeological Perspectives. New York: Seminar Press.

Binford, Lewis R. 1972a. "Archaeology as Anthropology", dalam Lewis R. Binford, An Archaeological Perspectives. New York: Seminar Press, hlm. 20-32.

Binford, Lewis R. 1972b. “Archaeological Perspectives", dalam Lewis R. Binford, An Archaeological Perspectives. New York: Seminar Press, hlm. 78- 104.

Binford, Lewis R. 1972c. "Some Comments on Historical Versus Processual Archaeology", dalam Lewis R. Binford, An Archaeological Perspectives. New York: Seminar Press, hlm. $114-124$. 
Chalmers, A.F. Apa itu yang Dinamakan IImu?. (Judul asli: What is this thing called Science?), Terjemahan Penerbit Hasta Mitra, Jakarta: Hasta Mitra. 1983.

Clarke, David L. Spatial Archaeology. London: Academic Press. 1977. Analytical Archaeology. London: Methuen. New York: Columbia University Press. 1978.

Daniel, Glyn E. The Origins and Growth of Archaeology. Harmondswor th: Pelican Books. 1967.

Deetz, James F. Invitation to Archaeology. New York : American Museum Science Books. 1967. "Must Archaeologist Dig?", dalam James F. Deetz (ed.), Man's Imprint from the Past, Boston: Little, Brown and Company, hlm. 2-9.1971.

Flannery, Kent V. "Culture History Versus Cultural Process: A Debate in American Archaeology", dalam Mark P. Leone (ed.), Contemporary Archaeology: A Guide to Theory and Contributions, Carbondale: Southern Illinois University Press, hlm. 102-107.1975.

Hadimuljono, "Riwayat Penyelidikan Prasejarah di Indonesia", dalam Satyawati Suleiman et al. (eds.), 50 Tahun Lembaga Peninggalan Purbakala Nasional, Jakarta : Pusat Penelitian Arkeologi Nasional, hlm. 60-103.1977.

Hodder, lan dan Clive Orton. Spatial Analysis in Archaeology. Cambridge: Cambridge University Press. 1976.

Hole, Frank dan Robert F. Heizer. An introduction to Prehistoric Archaeology. New York: Holt, Rinehart \& Winston. 1973.

Joukowsky, Martha. Field Archaeology: Tools and Techniques of Field Work for Archaeologist, Englewood Cliffs - New Jersey: Prentice Hall Inc. 1980. 
Jujun S. Soeriasumantri. "Tentang Hakekat Ilmu: Sebuah Pengantar Redaksi", dalam Jujun S. Soeriasumantri (ed.), Ilmu Dalam Perspektif. Jakarta: Gramedia, hlm. 1-40. 1981. Filsafat Ilmu. Jakar ta: Penerbit Sinar Harapan. 1984.

Jujun S. Soeriasumantri. (ed.). Ilmu Dalam Perspektif. Jakarta: Gramedia. 1981.

Koentjaraningrat. Beberapa Methode Anthropologi dalam Penjelidikan-penjelidikan Masjarakat dan Kebudayaan di Indonesia, disertasi Universitas, Jakarta: Universitas Indonesia. 1958. Kebudayaan, Mentalitet dan Pembangunan. Jakarta: Gramedia. 1974.

Kuhn, Thomas S. The Structure of Scientific Revolution. Chicago: The University of Chicago Press, second edition enlarged. 1970.

Longacre, William A. Archaeology as Anthropology: A Case Study, Nthropological papers of the University of Arizona No. 17, Tucson: The University of Arizona Press. 1970.

Mangunwijaya, Y.B. Teknologi dan Dampak Kebudayaannya. Vol 1, Jakar ta: Yayasan Obor Indonesia. 1983.

Martin, Paul. "The Revolution in Archaeology", dalam American Antiquity 36 (1): 1-8, Salt Lake City. 1971.

Miksic, John N. "Perkembangan Teknologi, Pola Ekonomi, dan Penafsiran Data Arkeologi Indonesia", dalam Majalah Arkeologi, IV (2): $1-16.1981$.

Mindra Faizaliskandiar. 1985. Arkeologi Indonesia 1953-1984: Kecenderungan dan Perkembangannya, Skripsi Bidang Arkeologi, Jakar ta: FSUI.

Mindra Faizaliskandiar. 1989. "Variabilitas Tipe Artefak Sebagai Indikator Strategi Subsistensi: Kajian Atas Strategi Perburuan Paleolitik Asia Tenggara”, dalam Pertemuan Ilmiah Arkeologi V, Buku ke-3. 
Mindra Faizaliskandiar. 1990. "Spesialisasi Dalam Arkeologi Indonesia: Zaman atau Tema?", dalam Edi Sedyawati et al. (eds.), Monumen: Karya Persembahan Untuk Prof. Dr. R. Soekmono, Jakarta: Fakultas Sastra Universitas Indonesia.

Mundardjito.1972. Arkeologi Masa Kini: Segi Metode dan Teknik, prasaran dalam penataran arkeologi di Borobudur.

Mundardjito. 1980. "Wadah Pelebur Logam dari Ekskavasi Banten 1976, Sumbangan Data Bagi Sejarah Teknologi”, dalam Pertemuan Ilmiah Arkeologi 1977, Cibulan. 